\section{Effect of Self-Etching Primer Associated to Hydrofluoric acid or Silane on Bonding to Lithium Disilicate}

Fabiana Suelen Figuerêdo de Siqueira ${ }^{1} \mathbb{B}$, Veridiana Silva Campos $^{2}$, Michel Wendlinger ${ }^{3}$, Rosa Ana Chiluisa Muso ${ }^{4}$, João Carlos Gomes²@, Alessandra Reis $^{2}$, Andres Felipe Millan Cardenas ${ }^{1}$, Alessandro D. Loguercio ${ }^{2,4}{ }^{-0}$

To evaluate the effect of combining 5\% hydrofluoric acid (HF) and silane (SI) with the selfetching ceramic primer on the immediate and after 1-year of water storage on bonding efficacy, conditioning pattern (CP) and chemical interaction $(\mathrm{Cl})$ to the lithium disilicate. A total of 16 CAD/CAM blocks of lithium disilicate (LD) were cut into four square sections $(n=64)$. For bonding efficacy evaluation, the LD specimens were divided into 4 groups $(\mathrm{n}=10):$ 1) $\mathrm{HF}+\mathrm{Sl}$; 2) self-etching ceramic primer (MEP); 3) HF+MEP; 4) MEP+SI. After each treatment, an adhesive system was applied and Tygon matrices were filled with a dualcured resin cement followed by light curing. Cylinder specimens $(0.8 \mathrm{~mm} \varnothing \times 0.5 \mathrm{~mm})$ were stored in water $\left(37^{\circ} \mathrm{C}\right.$ for $24 \mathrm{~h}$ or 1-year) and submitted to the $\mu$ SBS test (2-way ANOVA and Tukey's test; $\alpha=0.05)$. CP and $\mathrm{Cl}$ were only evaluated qualitatively. No significant difference on the $\mu S B S$ was observed between groups ( $p=0.73$ ), but reduced $\mu$ SBS was observed after 1 -year of water storage $(p>0.0001)$. After application of $\mathrm{HF}+\mathrm{SI}$ and MEP, reduction in a number of siloxane bonds was observed, suggesting the coupling of SI on the LD surface. HF or HF+MEP produced a higher dissolution of the glassy matrix than the use of MEP alone. The MEP can be an alternative to traditional ceramic treatment once the chemical interaction and long-term bond strength were similar between both groups. The association of hydrofluoric acid or silane with a self-etching ceramic primer did not add any benefits in terms of chemical interaction and bonding stability.
'Department of Postgraduate Program in Dentistry, CEUMA Centro de Ensino Unificado do Maranhão, São Luis, MA, Brazil ${ }^{2}$ Department of Restorative Dentistry, UEPG - Universidade Estadual de Ponta Grossa, Ponta Grossa, PR, Brazil ${ }^{3}$ Department of dentistry, CEUMA - Centro de Ensino Unificado do Maranhão, São Luis, MA, Brazil ${ }^{4}$ Facultad Ciencias de la Salud Eugenio Espejo, Universidade UTE, Quito, Ecuador

Correspondence: Prof. Dr. Alessandro D. Loguercio, Avenida Carlos Cavalcanti, 4748, Bloco M, Sala 64A, 84030- 900 Ponta Grossa, PR, Brasil. Tel: +55-42-3220-300. e-mail: aloguercio@hotmail.com

Key word: hydrofluoric acid, shear strength, silanes, adhesion.

\section{Introduction}

Recent improvements in the mechanical properties of lithium disilicate made it one of the most common materials for fabrication of indirect restoration in dental practice (1). Its excellent esthetics and mechanical properties (2) result in restorations with high survival rates (3). However, achieve a good bonding during luting protocols is also of paramount importance for the success of indirect lithium disilicate restorations (4).

Specifically, for lithium disilicate, the micromechanical interlock is created after conditioning with hydrofluoric acid by the selective glass matrix removal, promoting an increase of the ceramic roughness and more surface energy, followed of the silane application to promote a bifunctional and durable adhesion (5).

Although hydrofluoric acid is the suggested pretreatment for lithium disilicate restorations, this etchant is toxic (6) and depending on the concentration and etching time may also weaken the ceramic surface (7). Furthermore, the manufacturer recommends etching with $5 \% \mathrm{HF}$ for 20 seconds. However, there is no consensus on HF concentration and etching time in the literature, as such, variables vary across the published literature (8).
Recently, a self-etching ceramic primer (Monobond Etch \& Prime) was launched in the market. The self-etching ceramic primer is more versatile because it includes the etchant and the silane in a single bottle (9). According to the manufacturer, these novel material reduces the toxic potential of the $\mathrm{HF}$, the chair-time required and the technique sensitivity of etching ceramic when compared to the conventional methods (9). It was shown that the selfetching ceramic primer promotes less-pronounced etching pattern than that produced by the two-step procedure involving hydrofluoric acid and silane $(10,11)$.

Although this shallow etching pattern did not jeopardize immediate bond strength $(10,11)$, it may reduce the longevity of the bond strength of the ceramic interface with the silane agent. Thus, a preliminary etching with hydrofluoric acid before the use of the self-etching ceramic primer could be an alternative to improve the etching pattern and prolong the lifetime of the lithium disilicate bonds.

According to the manufacturer of ceramic primer, a thin layer of the methacrylate silane present in the self-etching ceramic primer remains chemically bonded to the lithium disilicate after water rinsing (9). Whether or not this thin 
silane coupling layer is enough to maintain a long-term bond strength to lithium disilicate is yet to be addressed. Perhaps, the application of a new layer of silane coupling agent, after the use of the self-etching ceramic primer, could saturate the surface of the lithium disilicate with more silane, improving the long-term durability of such bond. However, such an approach has never been tried thus far.

Most of the comparisons between the self-etching ceramic primer and the two-step hydrofluoric acid + silane procedure show similar immediate bond strength values $(10,11)$, and the few comparisons about the long-term bond strength values show inconsistent results $(12,13)$.

Thus, the aim of the present study was to evaluate the effect of the combination of hydrofluoric acid or silane with the self-etching ceramic primer on the immediate and after 1-year of water storage on bonding efficacy, morphological etching pattern and chemical interaction of these bonding treatments to the lithium disilicate. The following null hypotheses were evaluated in the present study: [1] the combination of hydrofluoric acid or silane with the self-etching ceramic primer will not influence the bonding efficacy immediate and after 1-year of water storage; [2] the association of hydrofluoric acid with the self-etching ceramic primer does not improve the chemical interaction to lithium disilicate when compared to the use of a separate hydrofluoric acid or a separate self-etching ceramic primer and; [3] the association of hydrofluoric i. we self-etching ceramic primer does not improve the morphological etching pattern to lithium disilicate compared to the use of a separate hydrofluoric acid or a separate self-etching ceramic primer.

\section{Material and Methods}

\section{Specimen Preparation and Experimental Design}

A total of 16 CAD/CAM blocks $(12 \times 12 \times 6 \mathrm{~mm})$ of LD (IPS e.max CAD; Ivoclar Vivadent, Schaan, Liechnstein) were used in the study. Each block was cut into four square sections ( $6 \times 6 \times 6 \mathrm{~mm} ; \mathrm{n}=64)$ using a diamond disk cutter attached to a low-speed saw (Isomet, Buehler; Lake Bluff, IL, USA) using water as a coolant. After ultrasonic cleaning in distilled water for $15 \mathrm{~min}$, the ceramic specimens were calcined following heating ramp from $25^{\circ} \mathrm{C}$ to $850{ }^{\circ} \mathrm{C}$ for 20-31 min using a furnace (Programat P300, Ivoclar Vivadent) $(10,14)$.

The 64 specimens were randomly divided for evaluation using three different methodologies. Forty were used for microshear bond strength ( $\mu \mathrm{SBS}$ ) testing, 12 specimens were used for evaluation of chemical interaction of MEP with the ceramic surface by Raman spectroscopy and 12 specimens were used for etching pattern.

Sample size calculation for bond strength to lithium disilicate was performed. The bond strength values of standard procedure were considered for sample size calculation. According to the literature $(12,14)$, mean and standard deviation of $\mathrm{HF}+\mathrm{SI}$ was 30.6 \pm 2.0 . Using an $\alpha$ of 0.05 , a power of $90 \%$ for equivalent test and a two-sided test, the minimal sample size was 10 specimens in each group in order will excluded a difference in means of more than $3 \mathrm{MPa}$ among the tested groups.

\section{Microshear Bond Strength ( $\mu S B S$ )}

To determine microshear bond strength test, the following experimental groups were formed:

Group 1: two-step procedure [HF + SI]: 5\% hydrofluoric acid (Fgm Prod. Odont. Ltda, Joinville, SC, Brazil) + silane coupling agent (Monobond P (Ivoclar Vivadent, Schaan, Liechnstein);

Group 2: self-etching ceramic primer [MEP]: Monobond Etch \& Primer (MEP; Ivoclar Vivadent, Schaan, Liechnstein);

Group 3: acid + self-etching ceramic primer [HF + MEP]: hydrofluoric acid + Monobond Etch \& Primer;

Group 4: Monobond Etch \& Primer + Monobond P [MEP + SI].

Forty specimens were mounted on a polyvinyl chloride (PVC) ring filled with acrylic resin (AutoClear, DentBras, Pirassununga, SP, Brazil) displaying the specimen surface on the top of the cylinder, with a height of $3 \mathrm{~mm}$. The specimens were etched following the details of individual experimental groups as above. The specimens were thoroughly rinsed with water (spray for $30 \mathrm{~s}$, Table 1). The adhesive system (Excite ${ }^{\circledR}$ F DSD, Ivoclar-Vivadent Inc, Amherst, NY, USA) was applied as recommended (Table 1).

Then, eight polyethylene transparent Tygon tubes (Tygon Medical Tubing Formulations 54-HL, Saint Gobain Performance Plastics, Akron, $\mathrm{OH}, \mathrm{USA})$, with an internal diameter of $0.8 \mathrm{~mm}$ and a height of $0.5 \mathrm{~mm}$ were positioned over each ceramic specimen $(14,15)$. A dual-cured resin cement (Variolink ${ }^{\circledR}$ II, Ivoclar-Vivadent Inc, Amherst, NY, USA) was mixed and carefully packed inside each tube, and a clear Mylar matrix strip was placed over the filled Tygon tube and pressed gently into place. The luting composite specimens were simultaneously light-cured for 20 s using a LED light-curing unit set at $1200 \mathrm{~mW} / \mathrm{cm}^{2}$ (Radii-cal, SDI, Victoria, Australia) in close contact with the mylar strip. A radiometer (Demetron L.E.D. Radiometer, Kerr Sybron Dental Specialties, Middleton, WI, USA) was used to check the light intensity every 8 luting composite cylinders. These procedures were carried out under magnifying loupes (15). A single operator performed all bonding procedures.

After storage of the specimens in distilled water for 24 $\mathrm{h}$ at $37{ }^{\circ} \mathrm{C}$, the Tygon tubes were carefully removed with a blade to expose the cement cylinders. Each specimen was examined under a stereomicroscope at $10 \times$ magnification. The cement cylinder was discarded if there was an evidence 
of porosity or gaps at the interface.

Half of the specimens of each experimental group were stored in water at $37{ }^{\circ} \mathrm{C}$ for 1 year. The other half were tested after stored in water at $37{ }^{\circ} \mathrm{C}$ for $24 \mathrm{~h}$. During storage at $37^{\circ} \mathrm{C}$, the specimens were placed in hermetically sealed vials to prevent evaporations and the distilled water was change monthly.

The specimens were attached to a shear testing fixture (Odeme Biotechnology; Joaçaba, Luzerna, SC, Brazil) and tested in a universal testing machine (Kratos IKCL 3-USB, Kratos Equipamentos Industriais; Cotia, SP, Brazil). A thin orthodontic wire (0.2 $\mathrm{mm}$ diameter) was looped around the base of each composite cylinder, contacting the composite cement cylinder in half of its circumference. The setup was kept aligned (cement-ceramic interface, the wire loop and the center of the load cell) to ensure the correct orientation of the shear forces. The crosshead speed was set at $1 \mathrm{~mm} /$ min until failure $(14,15)$.

The $\mu \mathrm{SBS}$ values (MPa) were calculated by dividing the load at failure by the surface area $\left(\mathrm{mm}^{2}\right)$ to determine the shear bond strength. After testing, the specimens were examined under an optical microscope (SZH-131, Olympus; Tokyo, Japan) at $100 \times$ magnification to define the location of the bond failure. The failure mode was classified as cohesive in resin cement ([CR] failure exclusively within the resin cement), cohesive in ceramic ([CC] failure exclusively within ceramic), adhesive/mixed ([A/M] failure at the resin cement-ceramics interface that included cohesive failure of the neighboring substrates).

\section{Chemical interaction analysis by Raman Spectroscopy}

Four LD specimens were analyzed according to the following groups: 1) no treatment [LD]; 2) Hydrofluoric acid 5\% + silane coupling agent (Monobond P) and, 3)
Monobond Etch \& Primer (MEP), applied according to the manufacturer instructions (Table 1).

To obtain the vibrational analysis, a Raman spectrometer (Horiba Scientific; Tokyo, Japan) was first calibrated for zero absorbance and then for coefficient values using a silicon test specimen. Specimens were analyzed using the following Raman configurations: $20 \mathrm{~mW}$ HeNe laser with $632.8 \mathrm{~nm}$ wavelength, spatial resolution of $\approx 3 \mu \mathrm{m}$, spectral resolution $\approx 5 \mathrm{~cm}^{-1}$, accumulation time of $30 \mathrm{~s}$, with $2 \mathrm{co}-$ additions, and magnification of 100X (Olympus UK; London, UK), and a beam diameter of $1 \mu \mathrm{m}$ in a wavenumber range of 800 to $4000 \mathrm{~cm}^{-1}$.

Firstly, spectra from silane [SI] (Monobond P), the selfetching ceramic primer [MEP] and LD ceramic were taken separately. Then specimens were treated according to their respective groups as described below. After application of the products (Monobond P or Monobond Etch \& Primer), the specimens were subsequently rinsed for $1 \mathrm{~min}$ in distilled water (30 s) and absolute ethanol (30 s), as described by Cardenas et al. (14) and Yoshihara et al. (16). The spectra were obtained in triplicate and a comparison for qualitative analysis was carried out and the chemical shift and intensity of each peak were processed for baseline corrections and normalized.

\section{Ceramic Etching Pattern}

To obtain ceramic etching patterns, three specimens per group were conditioned according to the following groups:

1) no conditioning [LD]; 2) Hydrofluoric acid 5\% [HF];

3) Monobond Etch \& Primer [MEP] and; 4) Hydrofluoric acid 5\% + Monobond Etch \& Primer [HF + MEP].

The materials were applied according to the manufacturer instructions (Table 1); dried and dehydrated in a desiccator for $12 \mathrm{~h}$. The ceramic surfaces were sputter with

Table 1. Materials used, batch number, composition and application mode (*)

\begin{tabular}{|c|c|c|}
\hline $\begin{array}{l}\text { Material, Manufacture } \\
\text { (Batch number) }\end{array}$ & Composition & Application mode \\
\hline $\begin{array}{l}\text { Hydrofluoric acid 5\% } \\
\text { (HF), FGM (110615) }\end{array}$ & $\begin{array}{l}\text { Hydrofluoric acid 5\%, Water, thickener, } \\
\text { Surfactant and colorant }\end{array}$ & $\begin{array}{l}\text { Apply for } 20 \mathrm{~s} \text {, rinse with water for } 30 \mathrm{~s} \text {, } \\
\text { ultrasonically clean with distilled water for } 180 \mathrm{~s}\end{array}$ \\
\hline $\begin{array}{l}\text { Monobond Plus (SI), } \\
\text { Ivoclar-Vivadent } \\
(1401001210)\end{array}$ & $\begin{array}{l}\text { Ethanol, 3-trimethoxysilylpropyl methacrylate, } \\
\text { methacrylated phosphoric acid ester, disulfide acrylate }\end{array}$ & $\begin{array}{l}\text { Apply with a brush, allow to react for } 60 \\
\text { s, and excess is dispersed with a strong air } \\
\text { stream to ensure solvent evaporation }\end{array}$ \\
\hline $\begin{array}{l}\text { Monobond Etch \&t } \\
\text { Prime (MEP), Ivoclar- } \\
\text { Vivadent (U10661) }\end{array}$ & $\begin{array}{l}\text { Buthanol, tetrabutylammonium dihydrogen } \\
\text { trifluoride, methacrylated phosphoric } \\
\text { acid ester, bis(triethoxysilyl)ethane }\end{array}$ & $\begin{array}{l}\text { Apply with a microbrush and rub for } 20 \mathrm{~s} \text {, remain } \\
\text { on the surface for } 40 \mathrm{~s} \text { and rinse thoroughly }\end{array}$ \\
\hline $\begin{array}{l}\text { Excite }^{\circledR} \text { F DSD } \\
\text { Ivoclar-Vivadent } \\
\text { (U23300) }\end{array}$ & $\begin{array}{l}\text { Urethane dimethacrylate, inorganic fillers, } \\
\text { ytterbium trifluoride, initiators, stabilizers, } \\
\text { pigments, fluoride, ethanol, silicon dioxide }\end{array}$ & $\begin{array}{l}\text { Mix the single-component, apply one coat } \\
\text { of the mixture for } 10 \mathrm{~s} \text {, air-dry for } 5 \mathrm{~s}\end{array}$ \\
\hline $\begin{array}{l}\text { Variolink }{ }^{\circledR} \text { II } \\
\text { Ivoclar-Vivadent } \\
\text { (U50748) }\end{array}$ & $\begin{array}{l}\text { Urethane dimethacrylate, inorganic fillers, ytterbium } \\
\text { trifluoride, initiators, stabilizers, pigments }\end{array}$ & $\begin{array}{l}\text { Mixture in a } 1: 1 \text { ratio on a mixing pad, } \\
\text { carefully pack the resin cement inside each } \\
\text { tube, light cure for } 20 \mathrm{~s} \text { at } 1200 \mathrm{~mW} / \mathrm{cm}^{2}\end{array}$ \\
\hline
\end{tabular}


gold/palladium in a vacuum evaporator (SCD 050, Balzers, Schaan, Liechtenstein), followed by an examination under a scanning electron microscope (MIRA3 LM, Tescan Orsay Holding, Warrendale, PA, USA). Three photomicrographs of representative surface areas were taken at $25.0 \mathrm{Kx}$ magnification $(10,14)$.

\section{Statistical Analysis}

The data were first analyzed using the KolmogorovSmirnov test to assess whether it followed a normal distribution and Barlett's test to examine the equality of variances (17). After confirming the normality of the data distribution and the equality of the variances, the $\mu$ SBS (MPa) data were subjected to appropriate statistical analysis.

The $\mu$ SBS obtained from the same specimen were averaged for statistical purposes. Two-way ANOVA (adhesive treatment vs. storage time) was used to analyze the $\mu$ SBS data, followed by Tukey's post-hoc test at $\alpha=0.05$. The chemical interaction and surface-etching pattern were only qualitatively evaluated.

\section{Results}

\section{Microshear Bond Strength ( $\mu S B S$ )}

Forty bonded cylinders were tested for each experimental group and none of them showed any pretesting failures or were discarded because of porosities or other defects. The majority of specimens showed adhesive/ mixed failures (Table 2).

The cross-product interaction adhesive treatment vs. storage time $(p=0.73)$ and the main factor adhesive treatment $(p=0.52)$ were not statistically significant. The samples from all experimental groups showed similar mean $\mu \mathrm{SBS}$ values to the conventional two-step hydrofluoric acid + silane group [HF + SI] (Table 3).

In regard to the storage time, a significant difference between experimental groups was observed $(p=0.001$; Table 3). For all the groups, lower mean $\mu S B S$ values were observed after 1-year storage time when compared to the values

Table 2. Number of specimens (\%) according to fracture mode for all experimental groups

\begin{tabular}{lcccccc}
\hline \multirow{2}{*}{ Groups } & \multicolumn{3}{c}{ Immediate } & \multicolumn{3}{c}{1 -year } \\
\cline { 2 - 7 } & A/M & CR & CC & A/M & CR & CC \\
\hline HF + SI & $40(100)$ & $0(0)$ & $0(0)$ & $40(100)$ & $0(0)$ & $0(0)$ \\
MEP & $39(98)$ & $1(2)$ & $0(0)$ & $40(100)$ & $0(0)$ & $0(0)$ \\
HF + MEP & $40(100)$ & $0(0)$ & $0(0)$ & $40(100)$ & $0(0)$ & $0(0)$ \\
MEP + SI & $38(95)$ & $2(5)$ & $0(0)$ & $40(100)$ & $0(0)$ & $0(0)$ \\
\hline
\end{tabular}

Abbreviations: A/M: adhesive/mixed fracture mode; CR: Cohesive in resin cement; CC: Cohesive in ceramic taken immediately after the sample preparation (Table 3 ).

\section{Chemical Interaction Analysis for Raman Spectroscopy}

Representative micro-Raman spectra of the samples from all groups are shown in Figure 1. Typical stretching peaks of the $\mathrm{Si}-0-\mathrm{Si}$ and $\mathrm{Si}-0$ in the region of 450 and $1100 \mathrm{~cm}^{-1}$, from the ceramic surface, were clearly detected, evidencing the presence of siloxane bonds (18). These peaks from the ceramic surface were reduced in intensity after application of SI and self-etching ceramic primer (MEP). The presence of the methacrylate groups was characterized by the observation of $1630 \mathrm{~cm}^{-1}[\mathrm{C}=\mathrm{C}]$ and $1710 \mathrm{~cm}^{-1}[\mathrm{C}=0$ ] vibrations in the Raman spectra. These vibrations can be linked to the methacrylate group of the silane molecule.

\section{Conditioning Pattern of the Ceramic Surface}

Figure 2 shows the representative scanning electron microscopy images of the conditioning pattern of the ceramic surface obtained after the application of different agents. The morphology of the non-treated lithium disilicate showed a smooth surface without any craters and pits. The hydrofluoric acid produced the highest dissolution of the vitreous matrix, producing a porous and rough surface. The self-etching ceramic primer (MEP) promoted a partial dissolution of the vitreous matrix, showing, comparatively, a lesser number of pores and a less rough surface (Fig. 2). The combined between the hydrofluoric acid and the self-etching ceramic primer (HF + MEP) did not show any morphological difference when compared to that seen with hydrofluoric conditioning alone (Fig. 2).

\section{Discussion}

Through the present study, it was observed that the sole use of the self-etching ceramic primer resulted in similar bonding properties compared with the combination with hydrofluoric acid or silane, immediately after sample preparation or after 1-year of water storage, leading to

Table 3. Means and standard deviations of microshear bond strength (MPa) values for all experimental groups

\begin{tabular}{lcc}
\hline Experimental Groups & Immediate & 1-year \\
\hline $\mathrm{HF}+\mathrm{SI}$ & $30.97 \pm 0.5 \mathrm{~A}$ & $16.89 \pm 1.0 \mathrm{~B}$ \\
$\mathrm{MEP}$ & $32.70 \pm 1.8 \mathrm{~A}$ & $16.86 \pm 0.7 \mathrm{~B}$ \\
$\mathrm{HF}+\mathrm{MEP}$ & $29.27 \pm 2.3 \mathrm{~A}$ & $17.81 \pm 1.9 \mathrm{~B}$ \\
$\mathrm{MEP}+\mathrm{SI}$ & $30.05 \pm 2.3 \mathrm{~A}$ & $17.86 \pm 0.8 \mathrm{~B}$ \\
\hline
\end{tabular}

HF + SI: 5\% hydrofluoric acid + Monobond P., MEP: Monobond Etch \& Primer, HF + MEP: hydrofluoric acid + Monobond Etch \& Primer, MEP + SI: Monobond Etch \& Primer + Monobond P. (*) Different letters indicate statistically significant differences among groups (2-way ANOVA, Tukey's test, $\mathrm{p}<0.05$ ) 
accept the first null hypothesis.

The silane coupling agent plays an important role on bonding to ceramic surfaces due to silane's bifunctional bonding ability. Silanes makes the ceramic surfaces more hydrophobic after silanization, optimizing the wettability of the luting resin cement on the ceramic surface (19). Furthermore, silane promotes stronger bonding with the lithium disilicate through siloxane linkages. The methoxy groups $\left(-\mathrm{Si}-\mathrm{OCH}_{3}\right)$, in presence of water, are hydrolyzed to silanols groups $(-\mathrm{Si}-\mathrm{OH})$ which can then bond with other

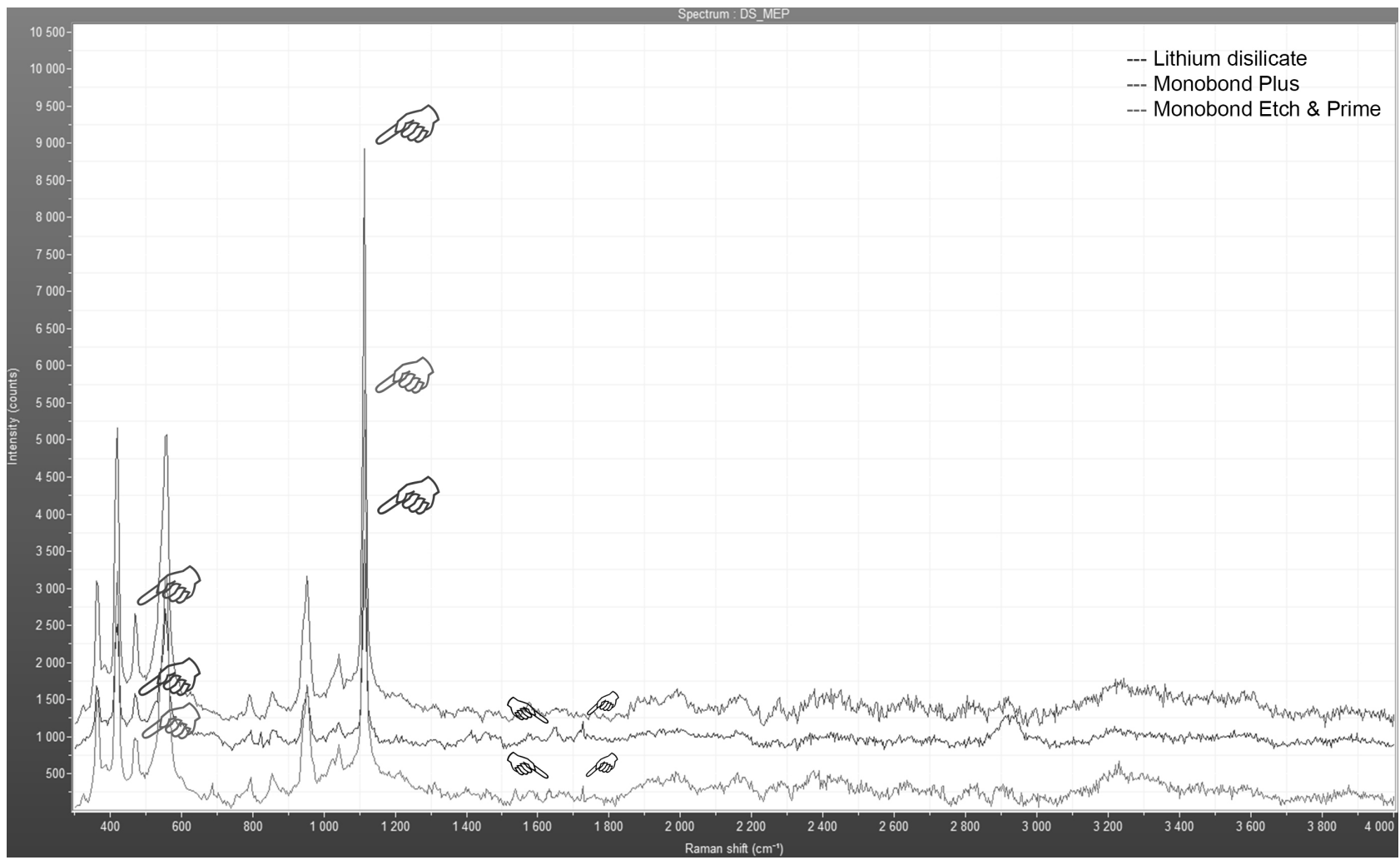

Figure 1. Representative Raman spectra for lithium disilicate (superior line), Monobond P (middle line) and Monobond Etch \& Prime (inferior line) after rinsing, suggesting the chemical interaction/adsorption capacity. Representative spectrum only of the lithium disilicate surface, in which Si-0$\mathrm{Si}$ and $\mathrm{Si}-0$ groups (strong peaks at 450 and $1100 \mathrm{~cm}^{-1}$ ) respectively can be identified. Raman signal detection after rising, the interaction of the SI and MEP application (higher hands in the medium and in the lower position) by the decreasing of peak characteristic silane groups (450 and 1100 $\mathrm{cm}^{-1}$ ). Peaks at $1630 \mathrm{~cm}^{-1}$ and $1710 \mathrm{~cm}^{-1}$ (lower hands) from $\mathrm{C}=\mathrm{C}$ and $\mathrm{C}=0$ vibration of 10-MDP can be observed after SI and MEP were applied.

LD

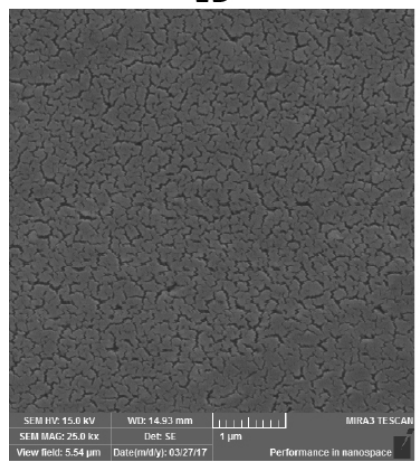

HF

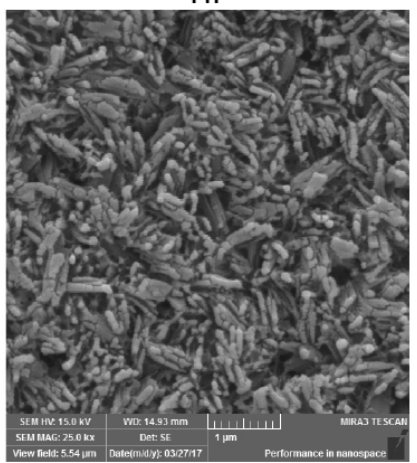

MEP

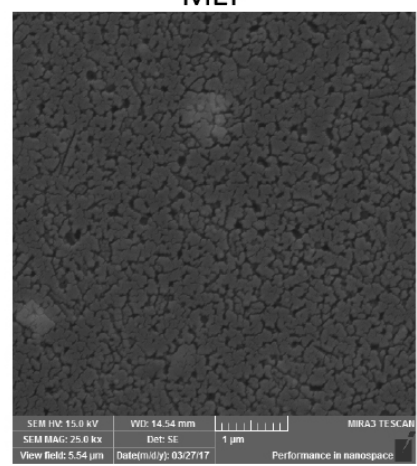

$\mathrm{HF}+\mathrm{MEP}$

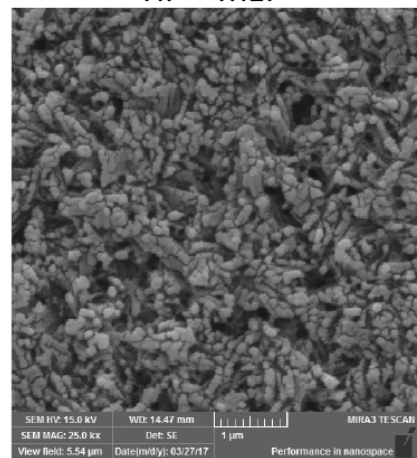

Figure 2. SEM Images showing the representative morphology of lithium disilicate surface untreated (LD) and treated with different conditioning agents evaluated in the present study $(25.0 \mathrm{Kx})$. Use of hydrofluoric acid (HF) resulted in an increase porous and irregular surface, due to the dissolution of the glass phase when compared to LD; When MEP was applied, there was only partial dissolution of the glassy matrix and the reduction in the roughness was observed (MEP). The association between HF + MEP did not show any significant changes in the morphology of LD. 
silanols on the surface of the lithium disilicate to produce a siloxane bond (Si-O-Si) (19).

According to the manufacturer's instruction, the self-etching ceramic primer contains trimethoxypropyl methacrylate that can attach to the ceramic surface or lithium disilicate surface to form a permanent thin layer which is stable even after rinsing and drying (9). It was could observe such an interaction through the decrease in the peak intensities of Si-O-SI $\left(450 \mathrm{~cm}^{-1}\right)$ and Si-O (1100 $\mathrm{cm}^{-1}$ ) groups on the lithium disilicate surface after MEP application, together with vibrations at $1630 \mathrm{~cm}^{-1}[\mathrm{C}=\mathrm{C}]$ and $1710 \mathrm{~cm}^{-1}[\mathrm{C}=0]$, which are likely to represent the methacrylate group of the silane molecule. The intensity of the methacrylate group was reduced after silane application (Fig. 2). Thus, it is hypothesized that the presence of silane in the composition of the self-etching ceramic primer is good enough to promote the formation of a functional silane nanolayer on the surface of lithium disilicate, leading to accept the second null hypothesis. It was responsible for an adequate interaction of the material with the surface of lithium disilicate and ultimately resulting in similar bond strength values for the samples from all the experimental groups.

Functional monomers, such as methacrylated phosphoric acid ester (10-MDP), have been added to the composition of silane solution and the self-etching ceramic primer in order to increase the potential for chemical interaction (20). 10-MDP is an efficient functional monomer frequently used for promoting chemical interaction (21) and is particularly associated with the use of metallic oxides, such as zirconia (22) and dental substrate. Methacrylate group, present in 10-MDP, helps copolymerization with further monomers in adhesives and resin cements, whereas its hydrophobic feature guarantees low hydrolytic degradation $(21,23)$. Thus, a reactive ceramic surface is formed by the bifunctional characteristic of the monomer that bonds the silica matrix and the resin cement.

So far, the adhesion of the 10-MDP functional monomers to lithium disilicate has not been reported. The peaks at $1630 \mathrm{~cm}^{-1}$ in Raman spectrum, which is relative to $\mathrm{C}=\mathrm{C}$ and $1710 \mathrm{~cm}^{-1}$, and also to $\mathrm{C}=0$ can also suggest adhesion of MDP to lithium disilicate surface as these vibrations, apart from the silane molecule, are also present in the methacrylate group of the 10-MDP. Further, focusing the use of Raman spectroscopy on the vibrations of phosphate group can provide further evidence of the bonding potential of MDP to the lithium disilicate surface.

It is worth noting that the results of this study in regard to significant reduction in mean bond strengths occurring over all the experimental groups after 1 year of storage under water is in agreement with previous studies reported by other authors $(4,8,14)$.
Adhesive systems used in bonding interfaces, are highly prone to water sorption (24) which may drain water from the environment causing not just plasticization of the polymer and reduction of its mechanical properties (24), but may also provide water for siloxane bond cleavage. When a silanized interface is exposed to water, a significant decrease of bond strength at the interface occurs over a period of time, which may be due to the hydrolytic cleavage of siloxane bonds in the siloxane $(4,8,14)$. As such, all of the above-discussed issues may contribute to reduced bond strength observed in all the experimental groups investigated in this study

The association between hydrofluoric acid + selfetching ceramic primer (HF + MEP) did not show any significant changes in the conditioning pattern of the lithium disilicate when compared to that produced by HF alone. On the other side, the self-etching ceramic primer alone promoted the less pronounced etching pattern, leading to partial reject the third null hypothesis. The results observed in the present study are in agreement with those reported by Siqueira et al. (10). The etching pattern produced by self-etching ceramic primer is achieved through the interaction of the ammonium poly fluoride with the ceramic surface. Ammonium poly fluoride is an acidic salt, with milder acidity than hydrofluoric acid, and therefore produces a partial dissolution of the glassy matrix than that produced by hydrofluoric acid, but still enough to promote an adhesive interlocking with the ceramic surface. So, the less-pronounced etching pattern produced by the self-etching ceramic primer cannot be seen as a disadvantage since it a more-pronounced etching pattern did not bring any significant benefits in terms of bond strength.

Similarly, when silane was applied together with the self-etching ceramic primer, no improvement in bond strength was observed. After conditioning, the glassy matrix is dissolved and the density of hydroxyl groups increases. It is known that these hydroxyl groups interact with silane coupling agents through hydrogen bond formation (19). Thus, authors hypothesize that the amount of free-hydroxyl groups (resulting from the partial glassy matrix dissolution which was promoted by the self-etching ceramic primer on the ceramic surface due to interaction with the silane) were totally consumed by the trimethoxypropyl methacrylate present in the composition of the self-etching ceramic primer, thus leaving no free hydroxyl groups for interaction with the extra layer of silane.

One of the limitations of this study was that only one type of resin cement used. Despite of the dual-cure resin cement still considered the "gold standard" for adhesive luting (5) the clinical's should watch cautiously since variations in chemical compositions, wetting ability, 
viscosity and mechanical properties might also influence the adhesive properties of each resin cement, hindering the replicate clinical (5). Future studies need to be done, evaluation the same present hypothesis but using different resin cement.

In summary, the present study demonstrated that self-etching ceramic primer (MEP) can produce superficial etching of the lithium disilicate surface and leave a silane bond attached to the surface that is capable to ensure microshear bond strength values similar to those resulting from the use of conventional two-step hydrofluoric acid + silane and self-etching ceramic primer associated with hydrofluoric acid or silane. These positive findings were recently observed in two case reports $(10,25)$. However, because the oral environment is more complex than current laboratory study, the present in vitro result must be interpreted with prudence and clinical trials should be carried out to continue evaluating the positive performance of the self-etching ceramic primer over longer periods of time.

The self-etching ceramic primer can be an alternative to traditional ceramic treatment once it is confirmed that chemical interaction and similar long-term bond strength are obtained when compared to those from traditional treatment. The association of hydrofluoric acid or silane coupling agent with a self-etching ceramic primer did not add any benefits in terms of chemical interaction and stability.

\section{Resumo}

Avaliar o efeito da combinação de ácido fluorídrico ou silano com o primer autocondicionante de cerâmicas sobre a eficácia da união imediata e após 1 ano de armazenamento em água, padrão de condicionamento e interação química desses tratamentos com o dissilicato de lítio. Um total de 16 blocos CAD/CAM de dissilicato de lítio (DL) foram cortados em quatro seções quadradas $(n=64)$. Os espécimes de $D L$ foram divididos em 4 grupos: 1) ácido fluoridrico a $5 \%+$ silano $(\mathrm{HF}+\mathrm{SI}) ; 2)$ primer autocondicionante de cerâmica (MEP); 3) HF + MEP; 4) MPE + SI. Após cada tratamento, o sistema adesivo foi aplicado e as matrizes Tygon foram preenchidas com cimento resinoso dual (Variolink ${ }^{\oplus} \mathrm{II}$ ), seguido de fotopolimerização. Espécimes em forma de cilindro $(0.8 \mathrm{~mm} \varnothing \times 0.5 \mathrm{~mm})$, foram armazenados em água $\left(37^{\circ} \mathrm{C}\right.$ por $24 \mathrm{~h}$ ou 1 ano) e submetidos ao teste $\mu$ SBS (ANOVA dois fatores e teste de Tukey; $\alpha=0,05$ ). Para avaliação das interações químicas por Espectroscopia Raman, os espécimes de DL foram divididos em 3 grupos ( $n=4): 1$ ) sem tratamento (DL);2) HF + SI; e 3) MEP. Para avaliação do padrão de condicionamento da superfície cerâmica após os tratamentos por MEV, os espécimes de DL foram divididos em 3 grupos ( $n=3):$ 1) DL; 2) HF; 3) MEP; e 4) HF + MEP. Ambos os métodos foram avaliados apenas qualitativamente. Não foi observada diferença significativa na $\mu$ SBS imediata entre os grupos $(p=0,73)$, mas após 1 ano de armazenamento das amostras em água, reduziu $\mu \mathrm{SBS}(p>0,0001)$. HF ou $\mathrm{HF}+\mathrm{MEP}$ produziram uma maior dissolução da matriz vitrea do que 0 uso de MEP sozinho. Após a aplicação de SI e MEP, observou-se redução de ligações de siloxano, sugerindo o acoplamento da camada de silano na superficie do DL. 0 primer autocondicionante cerâmico pode ser uma alternativa ao tratamento cerâmico tradicional, uma vez que a interação química e a resistência de união a longo prazo, quando comparada ao tratamento tradicional foram estatisticamente semelhantes. A associação de ácido fluoridrico ou agente de acoplamento silano com um primer autocondicionante de cerâmicas não agregou nenhum benefício em termos de interação quimica e estabilidade.

\section{Acknowledgments}

The authors do not have any financial interest in the companies whose materials are included in this article. This study was not funded by any sponsoring company. This study was partially supported by the National Council for Scientific and Technological Development (CNPq) under grants 305588/2014-1 and 303332/2017-4.

\section{References}

1. Mounajjed R, D ML, Azar B. The marginal fit of E.max Press and E.max CAD lithium disilicate restorations: A critical review. Dent Mater J 2016;35:835-844.

2. Gracis S, Thompson VP, Ferencz JL, Silva NR, Bonfante EA. A new classification system for all-ceramic and ceramic-like restorative materials. Int J Prosthodont 2015;28:227-235.

3. Gehrt M, Wolfart $S$, Rafai N, Reich $S$, Edelhoff D. Clinical results of lithium-disilicate crowns after up to 9 years of service. Clin Oral Investig 2013;17:275-284.

4. Guarda GB, Correr AB, Goncalves LS, Costa AR, Borges GA, Sinhoreti $M A$, et al. Effects of surface treatments, thermocycling, and cyclic loading on the bond strength of a resin cement bonded to a lithium disilicate glass ceramic. Oper Dent 2013;38:208-217.

5. Lise DP, Perdigao J, Van Ende A, Zidan 0, Lopes GC. Microshear bond strength of resin cements to lithium disilicate substrates as a function of surface preparation. Oper Dent 2015;40:524-532.

6. Ozcan M, Allahbeickaraghi A, Dundar M. Possible hazardous effects of hydrofluoric acid and recommendations for treatment approach: a review. Clin Oral Investig 2012;16:15-23.

7. Della Bona A, Anusavice KJ, Hood JA. Effect of ceramic surface treatment on tensile bond strength to a resin cement. Int J Prosthodont 2002;15:248-253.

8. Kalavacharla VK, Lawson NC, Ramp LC, Burgess JO. Influence of etching protocol and silane treatment with a universal adhesive on lithium disilicate bond strength. Oper Dent 2015;40:372-378.

9. Ivoclar-Vivadent. Monobond Etch \& Prime. Available from: http:// www.ivoclarvivadent.com/en/bonding-agents-luting-composites-torestorations/monobond-etch-and-prime. Latest access: November 7, 2018.

10. Siqueira FS, Alessi RS, Cardenas AF, Kose C, Souza Pinto SC, Bandeca $\mathrm{MC}$, et al. New Single-bottle Ceramic Primer: 6-month Case Report and Laboratory Performance. J Contemp Dent Pract 2016;17:1033-1039.

11. El-Damanhoury HM, Gaintantzopoulou MD. Self-etching ceramic primer versus hydrofluoric acid etching: Etching efficacy and bonding performance. J Prosthodont Res 2017.

12. Bright Chang, Nathaniel Lawson, Burgess J. Stability of silane to lithium disilicate in extreme environmental conditions. J Dent Res 2016;95:571-571.

13. De Goes M, Murillo-Gómez F. Long-term bond strength of glassceramic treated with acid ceramic primer. Dental Materials 33:e24.

14. Cardenas AM, Siqueira F, Hass V, Malaquias $P$, Gutierrez MF, Reis A, et al. Effect of MDP-containing silane and adhesive used alone or in combination on the long-term bond strength and chemical interaction with lithium disilicate ceramics. J Adhes Dent 2017;19:203-212.

15. Munoz MA, Baggio R, Emilio Mendes YB, Gomes GM, Luque-Martinez I, Loguercio AD, et al. The effect of the loading method and cross-head speed on resin-dentin microshear bond strength. Int J Adhes Adhes 2014;50:136-141.

16. Yoshihara K, Yoshida $Y$, Hayakawa S, Nagaoka N, Torii $Y$, Osaka A, et al. Self-etch monomer-calcium salt deposition on dentin. J Dent Res 2011;90:602-606.

17. Montgomery DC. Design and analysis of experiments. 5th ed. New York: John Wiley \& Sons. 1991.

18. Kitamura N, Fukumi K, Mizoguchi H, Makihara M, Higuchi A, Ohno N, et al. High pressure densification of lithium silicate glasses. Journal of Non-Crystalline Solids 2000;274:244-248.

19. Matinlinna JP, Lung CYK, Tsoi JKH. Silane adhesion mechanism in dental 
applications and surface treatments: A review. Dent Mater 2018;34:1328.

20. de Souza G, Hennig D, Aggarwal A, Tam LE. The use of MDP-based materials for bonding to zirconia. J Prosthet Dent 2014;112:895-902.

21. Feitosa VP, Ogliari FA, Van Meerbeek B, Watson TF, Yoshihara K, Ogliari $A 0$, et al. Can the hydrophilicity of functional monomers affect chemical interaction? J Dent Res 2014;93:201-206.

22. Xie H, Tay FR, Zhang F, Lu Y, Shen S, Chen C. Coupling of 10-methacryloyloxydecyldihydrogenphosphate to tetragonal zirconia: Effect of $\mathrm{pH}$ reaction conditions on coordinate bonding. Dent Mater 2015;31:218-225.
23. Nagaoka N, Yoshihara K, Feitosa VP, Tamada Y, Irie M, Yoshida Y, et al. Chemical interaction mechanism of 10-MDP with zirconia. Sci Rep 2017;7:455-463.

24. Reis A, Wambier L, Malaquias T, Wambier DS, Loguercio AD. Effects of warm air drying on water sorption, solubility, and adhesive strength of simplified etch-and-rinse adhesives. J Adhes Dent 2013;15:41-46.

25. de Siqueira F, Cardenas A, Gruber YL, Kose C, Pupo YM, Gomes GM, et al. Using CAD/CAM-Modified Correlation Mode to Produce Laminate Veneers: A Six-Month Case Report. Oper Dent 2017;42:139-147.

Received June 18, 2018 Accepted October 11, 2018 